\title{
Painful neuropathic disorders: An analysis of the Régie de l'Assurance Maladie du Québec database
}

\author{
J Lachaine $\mathrm{PhD}^{1}, \mathrm{~A}$ Gordon $\mathrm{MD} F \mathrm{FCP}{ }^{2}, \mathrm{M}$ Choinière $\mathrm{PhD}^{3}$, JP Collet $\mathrm{MD} \mathrm{PhD}^{4}$, D Dion $\mathrm{MD}^{5}$, J-E Tarride $\mathrm{PhD}^{6}$
}

J Lachaine, A Gordon, M Choinière, JP Collet, D Dion, J-E Tarride. Painful neuropathic disorders: An analysis of the Régie de l'Assurance Maladie du Québec database. Pain Res Manage 2007;12(1):31-37.

BACKGROUND/OBJECTIVE: Painful neuropathic disorders (PNDs) refer to neurological disorders involving nerves in which pain is a predominant symptom. In most cases, PNDs involve the peripheral nerves. Treatment of PNDs is likely to use large health care resources. However, little is known about the economic burden of PNDs in Canada.

METHOD: The present study was performed using data from a random sample of patients covered by the Régie de l'Assurance Maladie du Quebec drug plan. Subjects with a diagnosis of a peripheral PND were identified. Comorbidities, pain-related medication use and resource utilization were compared between PND patients and control patients without PNDs matched for age and sex in a 1:1 ratio.

RESULTS: A total of 4912 patients with PNDs were identified. A higher level of comorbidities was found in the PND group (Von Korff chronic disease score 3.91 versus 2.54; $\mathrm{P}<0.001)$. The proportion of users of pain-related medications was significantly higher in the PND cohort than in the control group $\left(\chi^{2} ; \mathrm{P}<0.001\right)$. The average annual number of physician visits was also significantly higher in the PND group than in the control group $(14.7$ versus $6.4 ; \mathrm{P}<0.001)$. From a health ministry perspective, costs of health care resources were significantly higher in the PND group $(\$ 4,163$ versus $\$ 1,846 ; \mathrm{P}<0.001)$. The proportion of potentially inappropriate medications was $34 \%$ among those 65 years of age or older.

CONCLUSIONS: PNDs are associated with a higher level of comorbidities, higher medical resources utilization and higher health care costs than non-PND conditions.

Key Words: Comorbidities; Cost analysis; Inappropriate prescribing; Painful neuropathic disorders

\section{Les troubles de douleur neuropathique : Une analyse de la base de données de la Régie de l'assurance maladie du Québec}

HISTORIQUE ET OBJECTIFS : Les troubles de douleur neu-
ropathique (TDN) désignent les troubles neurologiques d'origine
nerveuse dont la douleur est le principal symptôme. Dans la plupart des
cas, les TDN touchent les nerfs périphériques. Selon toute probabilité, il
faut faire grand usage des ressources de santé pour les traiter. Cependant,
on ne sait pas grand-chose du fardeau économique que représentent les
TDN au Canada. MÉTHODOLOGIE : Pour effectuer la présente étude, on a fait appel aux données d'un échantillon aléatoire de patients couverts par le régime d'assurance-médicaments de la Régie de l'assurance maladie du Québec. On a repéré les sujets atteints de TDN périphériques diagnostiqués. On a ensuite comparé les comorbidités, le recours aux médicaments reliés à la douleur et l'utilisation des ressources entre les patients souffrant de TDN et un groupe témoin ne souffrant pas de telles douleurs, appariés selon l'âge et le sexe, dans un ratio de un pour un.

RÉSULTATS : On a repéré un total de 4912 patients atteints de TDN. On a constaté un taux plus élevé de comorbidités au sein de ce groupe (indice de maladie chronique de Von Korff: 3,91 par rapport à 2,54; $\mathrm{P}<0,001)$. La proportion d'utilisateurs de médicaments reliés à la douleur était consi-dérablement plus élevée au sein de la cohorte souffrant de TDN que du groupe témoin $\left(\chi^{2} ; \mathrm{P}<0,001\right)$. Le nombre annuel moyen de consultations chez le médecin était également beaucoup plus élevé au sein du groupe souffrant de TDN que du groupe témoin (14,7 par rapport à 6,4; $\mathrm{P}<0,001)$. Du point de vue du ministère de la Santé, les coûts de ressources de santé étaient considérablement plus élevés au sein du groupe souffrant de TDN (4 163 \$ par rapport à 1846 ; $\mathrm{P}<0,001$ ). La proportion de médicaments potentiellement inappropriée était de $34 \%$ chez les patients de 65 ans ou plus.

CONCLUSIONS : Les TDN s'associent à un fort taux de comorbidités, à une plus forte utilisation des ressources médicales et à des coûts de santé plus élevés que les douleurs d'autre origine.
$\mathrm{N}$

europathic pain $(\mathrm{NeP})$ has been defined by the International Association for the Study of Pain as pain "initiated or caused by a primary lesion or dysfunction in the nervous system" (1). NeP includes a diverse group of pain syndromes, referred to as painful neuropathic disorders (PNDs), that share similar pathophysiological mechanisms but vary in etiology, clinical course and response to therapy. The various PNDs can be broadly divided into peripheral PNDs (eg, diabetic painful neuropathy $[\mathrm{DPN}]$, postherpetic neuralgia $[\mathrm{PHN}]$, trigeminal neuralgia) and central PNDs (eg, central poststroke pain, multiple sclerosis pain and Parkinson disease pain) (2). $\mathrm{NeP}$ is a chronic condition that may last for many years and severely

${ }^{1}$ Faculty of Pharmacy, University of Montreal, Montreal, Quebec; ${ }^{2}$ Wasser Pain Management Center, Mount Sinai Hospital and Division of Neurology, University of Toronto, Toronto, Ontario; ${ }^{3}$ Department of Anaesthesiology, Faculty of Medicine, University of Montreal;

${ }^{4}$ Department of Clinical Epidemiology, McGill University; ${ }^{5}$ Department of Family Medicine, University of Montreal, Montreal; ${ }^{6}$ At time of study: Pfizer Canada Inc, Kirkland, Quebec; Current affiliation: Department of Clinical Epidemiology and Biostatistics, Faculty of Health Sciences, McMaster University, Hamilton, Ontario

Correspondence and reprints: Dr Jean Lachaine, Faculty of Pharmacy, University of Montreal, PO Box 6128, Station Centre-ville, Montreal, Quebec H3C 3J7. Telephone 514-343-6111 ext 4873, fax 514-343-2102, e-mail jean.lachaine@umontreal.ca 
impact the quality of life of affected individuals. If inadequately treated, PNDs are often accompanied by anxiety, depression and sleep disturbances (3).

The burden of PNDs is not well documented in the Canadian literature. However, studies conducted in the United States (US) and Europe suggest that the economic and humanistic burden of PNDs is considerable. A recent study (4) conducted in a large US health insurance population indicated that the costs associated with patients with PNDs in 2000 were threefold higher for PND patients than non-PND patients. Another study (5) estimated the 1986 US expenditures at US\$240,000,000 (approximately \$297,000,000 in Canadian funds) for care of diabetic peripheral neuropathies. In Europe, a German study (6) estimated that the cost for diabetic patients with peripheral PND was 116,000,000 Deutsche Marks (approximately $\$ 94,000,000$ in Canadian funds). In the United Kingdom, using a one-year cohort of incident PHN subjects, the lifetime costs of treating PHN were estimated to range from 4.8 to 17.9 million British pounds sterling (approximately $\$ 11.1$ to $\$ 41.4$ million in Canadian funds) (7). In this study, over one-half of the patients reported that PHN had affected their ability to perform their usual activities for 1.5 years, on average. In another study conducted in Sweden (8), $52 \%$ of the 126 patients with $\mathrm{NeP}$ due to peripheral nerve or root lesion enrolled in the study had reduced their employment status as a direct consequence of their pain.

The treatment of $\mathrm{NeP}$ is difficult, and in many patients, requires the use of a combination of drug therapies including opioids, antidepressants, anticonvulsants and local anaesthetics, as well as various nonpharmacological techniques. While widely prescribed for PNDs, the medications do not have the indication for treatment of PNDs in Canada. In addition, in older adults, some of these medications may be potentially inappropriate for use due to their associated risk profile, as illustrated by a recent US study (9), which reported that almost one-half of the older adults with PNDs received one potentially inappropriate pain-related medication.

The management of PND is a major health care consideration, both from funding and treatment perspectives. However, to date, no study has sought to evaluate the economic impact of PNDs in Canada or the potential misuse of pain-related medications. The purpose of the present study was twofold: first, to describe the clinical and economic characteristics of patients with peripheral PNDs in one of the largest Canadian provinces (Quebec); and second, to estimate the use of potentially inappropriate pain-related medications among older adults with peripheral PNDs.

\section{METHODS}

A retrospective cohort study was conducted using data about pharmaceutical and medical services, as well as beneficiaries' demographics retrieved from the database of the Quebec provincial health plans (Régie de l'Assurance Maladie du Québec [RAMQ]). Quebec, like the other provinces in Canada, has a universal health care program, covering physicians' services and hospitalization for the whole population. This universal health care program is complemented, for a large proportion of the population, by a public drug plan. This provincial drug reimbursement program covers every person aged 65 years or older, the beneficiaries of the social assistance program and those individuals who do not have access to a private plan of medication insurance. As opposed to the health care plan in which all costs are covered by the plan, there is limited financial participation of the beneficiaries for the drug plan. In 2002 there were approximately 2,850,000 persons covered by the program. The RAMQ medical services database comprises information from physicians' claims for services provided within and outside the hospital. The RAMQ pharmaceutical services database includes information from pharmacists' claims for dispensed medications reimbursed by the program but not medications received in a hospital.

In accordance with RAMQ's restrictions on the number of subjects available for analyses by external parties, data were obtained for a random sample of subjects representing $15 \%$ of the population covered by the drug reimbursement program during the period from January 1, 2002, to December 31, 2002. Data obtained from the RAMQ included an encrypted patient identifier which enabled linkage of individual patient information while preserving anonymity. Because patients' data used for this study were anonymous, an ethical approval was not required to perform the analyses. For this random sample of unidentifiable subjects, data on all medications and medical services received during the period from January 1, 2002, to December 31, 2002, were obtained.

The study was performed according to the perspective of the publicly funded health plan of the province of Quebec in Canada. Accordingly to this perspective, only direct health care costs supported by the provincial health system were considered in the analyses.

\section{Study population}

Patients with a diagnosis of peripheral PND were identified. Diagnoses of peripheral PND considered in these analyses were identified by the International Classification of Diseases, Ninth Revision (ICD-9) codes found in the RAMQ database on medical services. As in Berger et al (4), the peripheral PND diagnoses (ICD-9 codes in parentheses) comprise: diabetic neuropathy $(2506,3572)$, PHN (0531), back pain with neuropathic involvement (7221, 7222, 7227, 7240, 7243, 7244), neck pain with neuropathic involvement $(7211,7220,7230,7234)$, cancer with neuropathic involvement (1400 to 1729,1740 to 2089 and 3372, 3532, 3533, 3534, 3544, 3557, 3559, 7292, 3530, $3531,3538,3539,3540,3541,3542,3543,3545,3548,3549$, 3550, 3551, 3552, 3553, 3554, 3555, 3556, 3558, 3573, 3578, 3579), causalgia, reflex sympathetic dystrophy and related disorders (3372, 3532, 3533, 3534, 3544, 3557, 3559, 7292), HIV/AIDS with neuropathic involvement (0420, 3372, 3532, 3533, 3534, 3544, 3557, 3559, 7292, 3530, 3531, 3538, 3539, $3540,3541,3542,3543,3545,3548,3549,3550,3551,3552$, 3553, 3554, 3555, 3556, 3558, 3573, 3578, 3579), phantom limb pain (3536), trigeminal neuralgia (3501), atypical facial pain $(3502,3521)$ and other disorders of the peripheral nervous system associated with $\mathrm{NeP}(3530,3531,3538,3539,3540,3541$, 3542 , 3543, 3545, 3548, 3549, 3550, 3551, 3552, 3553, 3554, $3555,3556,3558)$.

Subjects were included in the PND cohort if a diagnosis of a PND was found on at least two occasions in the patient's medical services file during the year 2002. Imposing two similar PND diagnoses during 2002 minimized misclassification bias due to a potentially inaccurate ICD-9 diagnosis that could result from coding errors. To compare our findings with a normal population, a control cohort matched for sex and age was created from a random sample of subjects with no diagnosis of a PND in 2002, in a 1:1 ratio. This matched control cohort was representative of the average population covered by the RAMQ drug plan for age and sex. 


\section{Analyses}

Characteristics of the study population (PND and control cohorts) were analyzed in terms of sex, age and comorbidities. The level of comorbidities was estimated by calculating a chronic disease score. This chronic disease score is an adaptation of the Von Korff et al score (10) that takes into account the medications introduced since the initial development of the score. Occurrences of selected medication use during year 2002 were used to calculate the chronic disease score. The prevalence of various comorbidities such as low back pain, arthritis, diabetes and depression was also estimated by searching in the database for the ICD-9 codes associated with these comorbidities. Results were then compared between study groups. To be reported as a comorbidity, the diagnostic code needed to be found on at least two occasions in 2002.

Proportions of users of pain-related medications (ie, anticonvulsants, antidepressants, nonsteroidal anti-inflammatory drugs [NSAIDs], benzodiazepines, corticosteroids, muscles relaxants, sedatives, hypnotics and opioids) were identified and compared between study groups. The proportion of potentially inappropriate use of pain-related medications in elderly patients was estimated using the Beers' criteria. First published in 1997 (11), the Beers criteria were recently updated to take into account the availability of new drugs and increased knowledge on the appropriate use of medications. The updated Beers criteria include 48 medications or classes of medications to avoid in older adults (ie, 65 years and older), as well as 20 diseases or conditions and the medications to be avoided in older adults with these conditions (12). For example, according to these criteria, muscle relaxants, antispasmodic drugs and amitriptyline should be avoided in elderly patients due to their strong anticholinergic and sedation properties. As an example of medications to be avoided in older adults with a particular condition, those with blood clotting disorders or receiving anticoagulant therapy should not take acetylsalicylic acid, NSAIDs, dipyridamole, ticlopidine and clopidogrel because they may prolong clotting time, elevate international normalized ratio values or inhibit platelet aggregation, resulting in an increased potential for bleeding (12).

Two additional analyses were conducted with respect to the appropriate use of amitriptyline and gabapentin, two products used in the treatment of PNDs. The appropriate use of amitriptyline was estimated according to contraindications, warnings and drug interactions reported in its Canadian product monograph. The average daily dosage of gabapentin was determined to document whether gabapentin was being used optimally.

Health care resources consumed by PND and non-PND patients were identified in terms of visits to physicians, physician interventions, pain-related medications, non-pain-related medications and hospitalizations. The number of days of hospitalization was estimated using the location of the physician encounter, as indicated in the medical services database. Costs associated with physicians' visits, procedures and medications were identified using the amounts reimbursed by the RAMQ. The cost of hospitalization was calculated using the average cost of one day of hospitalization in Quebec (\$624 in 2002) according to the Quebec Hospital Association.

Differences between PND and non-PND groups were tested for significance using $\chi^{2}$ and ANOVA. To account for potential confounding factors, ordinary least square (OLS) regression was conducted to assess the impact of several variables (ie, age, sex, level of comorbidities and PND diagnosis) on the cost reimbursed by the RAMQ. For the purpose of the regression, only the costs were transformed into a logarithmic form.

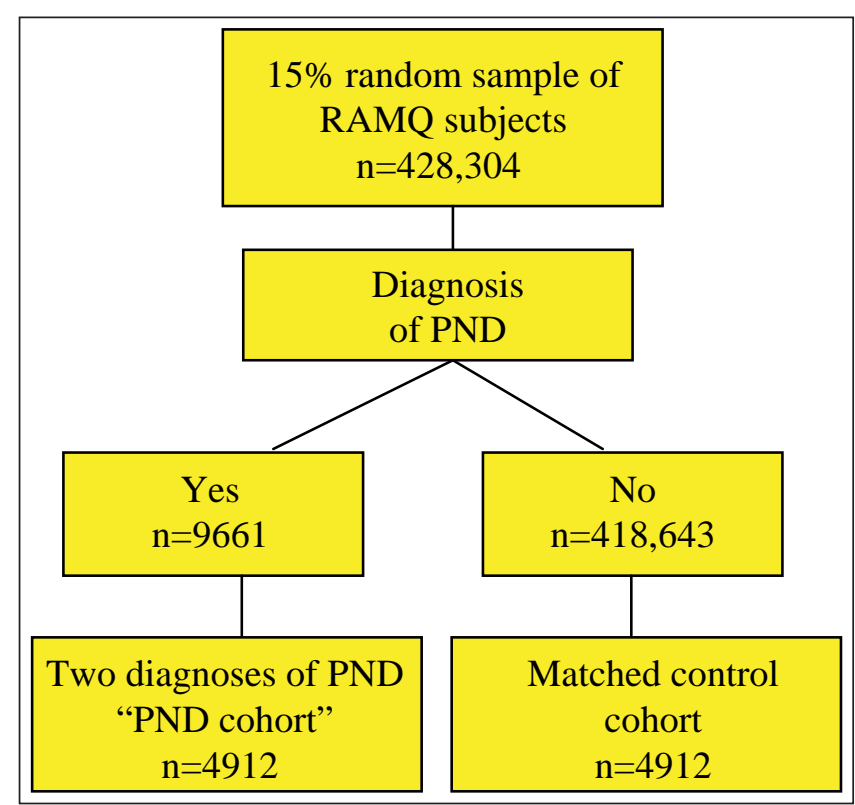

Figure 1) Extraction of the study population from the random sample of Régie de l'Assurance Maladie du Québec (RAMQ) patients. PND Painful neuropathic disorder

\section{RESULTS}

The $15 \%$ random sample of the patients covered by the provincial drug plan in 2002 comprised a total of 428,304 subjects. Of these, 9661 had at least one diagnosis of a PND and 4912 had at least two similar diagnoses of a PND in 2002. A random control cohort of 4912 patients with no diagnosis of a PND in 2002 that was matched for sex and age was created for comparison purposes (Figure 1).

The mean age of the study population was 57.4 years, and a higher proportion of subjects were female $(61.4 \%)$. There were 2043 patients older than 64 years of age. As indicated in Table 1, the most frequent PND diagnosis was causalgia (28.6\%), followed by carpal tunnel syndrome $(25.4 \%)$ and back pain $(24.3 \%)$. No patient was found with a diagnosis of cancer or AIDS/HIV with neuropathic involvement or phantom limb pain. The majority of patients had only one peripheral PND (Table 1).

The two methods used to assess comorbidities indicated that PND patients were more likely to have chronic comorbidities than non-PND patients. The Von Korff et al (10) chronic disease score was significantly higher for patients with PND than non-PND patients (3.91 versus 2.54, respectively; $\mathrm{P}<0.001)$. The second approach used the diagnostic codes found in the medical services database to evaluate the prevalence of selected chronic comorbidities (Table 2). PND patients had significantly more comorbidities than non-PND patients. The most common comorbidities observed in the present study population of PND patients were other arthritis, arthropathy and musculoskeletal pain (36.7\%), followed by other spinal pain $(21.1 \%)$, low back pain $(12.3 \%)$, diabetes (12.0\%), osteoarthritis (8.4\%) and depression (6.3\%). Among the PND patients, $70.9 \%$ had at least one comorbidity.

PND patients were more likely to receive pain-related medications than non-PND patients. As indicated in Table 3, NSAIDs (53.2\%), benzodiazepines (31.5\%), antidepressants (25\%), corticosteroids (21\%), opioids (19\%) and anticonvulsants $(13.8 \%)$ were widely used among PND patients. For all 
TABLE 1

Characteristics of patients with and without painful neuropathic disorders (PNDs)

\begin{tabular}{|c|c|c|}
\hline Characteristics & \multicolumn{2}{|c|}{ All patients $(n=9824)$} \\
\hline \multicolumn{3}{|l|}{ Age groups (years), n (\%) } \\
\hline$<40$ & \multicolumn{2}{|c|}{$823(16.8)$} \\
\hline $40-59$ & \multicolumn{2}{|c|}{$1662(33.8)$} \\
\hline $60-74$ & \multicolumn{2}{|c|}{$1582(32.2)$} \\
\hline$\geq 75$ & \multicolumn{2}{|c|}{$845(17.2)$} \\
\hline Average age, years & \multicolumn{2}{|c|}{57.4} \\
\hline \multicolumn{3}{|l|}{ Sex, n (\%) } \\
\hline Female & \multicolumn{2}{|c|}{$3018(61.4)$} \\
\hline \multirow[t]{2}{*}{ Male } & \multicolumn{2}{|c|}{$1894(38.6)$} \\
\hline & $\begin{array}{c}\text { Patients } \\
\text { with PNDs } \\
n=4912\end{array}$ & $\begin{array}{c}\text { Patients } \\
\text { without PNDs } \\
n=4912\end{array}$ \\
\hline Chronic disease score (mean $\pm \mathrm{SD}$ ) & $3.91 \pm 3.70$ & $2.54 \pm 3.16$ \\
\hline \multicolumn{3}{|l|}{ PND, n (\%) } \\
\hline Diabetic neuropathy & $100(2.0)$ & $\mathrm{n} / \mathrm{a}$ \\
\hline Postherpetic neuralgia & $5(0.1)$ & $\mathrm{n} / \mathrm{a}$ \\
\hline Back pain with neuropathic involvement & $1196(24.3)$ & $\mathrm{n} / \mathrm{a}$ \\
\hline Neck pain with neuropathic involvement & $108(2.2)$ & $\mathrm{n} / \mathrm{a}$ \\
\hline Cancer with neuropathic involvement & 0 & $\mathrm{n} / \mathrm{a}$ \\
\hline Causalgia, reflex sympathetic dystrophy & $1404(28.6)$ & $\mathrm{n} / \mathrm{a}$ \\
\hline HIVIAIDS with neuropathic involvement & 0 & $\mathrm{n} / \mathrm{a}$ \\
\hline Phantom limb pain & 0 & $\mathrm{n} / \mathrm{a}$ \\
\hline Trigeminal neuralgia & $50(1.0)$ & $\mathrm{n} / \mathrm{a}$ \\
\hline Atypical facial pain & $27(0.5)$ & $\mathrm{n} / \mathrm{a}$ \\
\hline Carpal tunnel syndrome & $1249(25.4)$ & $\mathrm{n} / \mathrm{a}$ \\
\hline Mononeuritis of upper limb, unspecified & $861(17.5)$ & $\mathrm{n} / \mathrm{a}$ \\
\hline \multicolumn{3}{|l|}{ system associated with neuropathic pain } \\
\hline \multicolumn{3}{|l|}{ Number of PNDs, n (\%) } \\
\hline One & $4683(95.3)$ & $\mathrm{n} / \mathrm{a}$ \\
\hline Two & $222(4)$ & $\mathrm{n} / \mathrm{a}$ \\
\hline Three & $7(0)$ & $\mathrm{n} / \mathrm{a}$ \\
\hline
\end{tabular}

n/a Not applicable

categories of pain-related medications, the proportion of users was significantly higher in the PND cohort (Table 3 ). On average, PND patients took pain medication therapy for $192 \pm 133$ days over this one-year time period.

Using the Beers criteria, the proportion of potentially inappropriate medications among PND patients aged 65 or older was $33.8 \%$. Potentially inappropriate medications included amitryptyline (11.2\%); long-term use of naproxen, oxaprozin or piroxicam $(7.1 \%)$; muscle relaxants and antispasmodics (6.8\%); and short- and long-acting benzodiazepines (6.6\%). The details of this analysis are presented in Table 4 . In addition, according to the amitriptyline product monograph, more than one-third $(36.1 \%)$ of all amitriptyline users had either a contraindication $(0.9 \%)$, a warning $(16.6 \%)$ or a drug interaction $(23.8 \%)$. The average dose of amitriptyline was $29.6 \mathrm{mg}$ per day. Gabapentin was used by 523 PND patients. The average daily dosage of gabapentin was $885 \pm 597 \mathrm{mg} ; 54.7 \%$ used less than $900 \mathrm{mg}$ per day and $6.7 \%$ used a dose of $1800 \mathrm{mg}$ per day or more.
Health resource utilization in 2002, including visits to general practitioners (GPs) and specialists, medical procedures performed by GPs and specialists, and number of days of hospitalization, was also significantly higher among PND patients than non-PND patients (Table 5). For example, the annual number of physician visits (GPs and specialists) in 2002 was 14.7 for PND patients and 6.4 for non-PND patients. Consequently, the amount reimbursed by the RAMQ was significantly higher for patients with $\operatorname{PND}(\$ 4,163)$ than for patients without PND $(\$ 1,846)$, as reported in Table 6 .

According to the results of the multivariate analyses, presence of a PND, the level of comorbidities (as estimated by the Von Korff scores), being female and age were significant variables in explaining the total cost of health care resources consumed by the study population. The model explained almost $50 \%$ of the variance $\left(\mathrm{R}^{2}=0.46\right)$. Presence of PNDs had the biggest impact on the total cost of health care resources consumed.

\section{DISCUSSION}

The findings of the present study indicate that the economic burden of PND is significant, with an average yearly incremental cost of $\$ 2,317$ per patient for health care resources associated with PND. The average cost of health care resources was reported to be 2.3-fold higher for PND patients than nonPND patients. In comparison, in a similar US study estimating health resources consumption over a one-year period, health care expenses were threefold higher for PND patients than matched control subjects (US\$17,355 versus US $\$ 5,715$, respectively) (4). Although a selection bias can account for some of these differences, the higher health care costs in the US compared with Canada has to be acknowledged (13). In addition, in the US study, $93.9 \%$ of patients had at least one comorbidity, while the percentage of patients with one comorbidity or more was $70.9 \%$ in the present study.

Results indicate that the use of potentially inappropriate pain-related medications among older adults with PND was common. When applying the updated Beers criteria, the proportion of potentially inappropriate pain-related medication use was $33.8 \%$ among older patients (ie, 65 years and older) with a diagnosis of a PND. In comparison, Oster et al (9) reported that in the US, $49.6 \%$ of PND patients aged 65 years and older received at least one potentially inappropriate pain-related medication. The fact that a high proportion of inappropriate propoxyphene use was found in this US study - a product not reimbursed by the RAMQ and therefore not observed as part of the present study - combined with an older US study population compared with our study population, may explain the higher proportion of potentially inappropriate medication utilization reported by Oster et al.

As in other studies using administrative databases, there are some inherent limitations. It is assumed that reimbursed medications retrieved from the databases were taken by the patient, although this may not have always been the case. In addition, samples received by the patient from his or her physician, medications received while hospitalized and medications not reimbursed by the drug plan, including over-the-counter medications, were not taken into account.

There are restrictions applied by the RAMQ on the maximum number of subjects from whom data can be obtained by external parties. The random sample of subjects representing $15 \%$ of the population covered by the drug plan use for the 
TABLE 2

The prevalence of chronic comorbidities in patients with and without painful neuropathic disorders (PNDs)

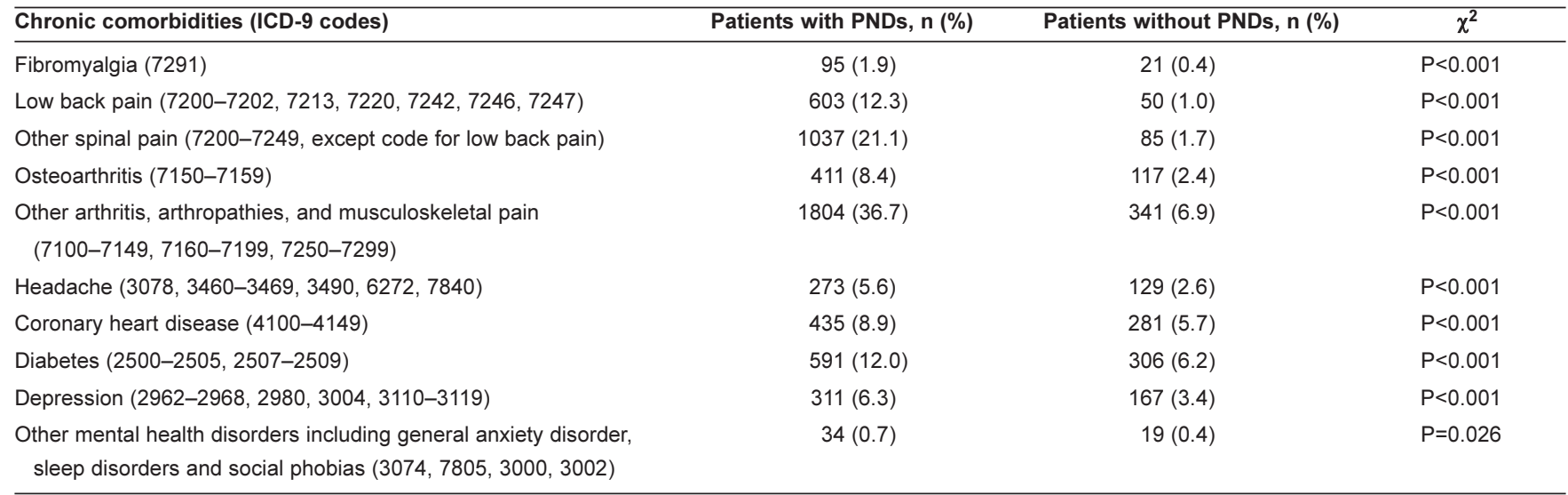

ICD-9 International Classification of Diseases, Ninth Revision

TABLE 3

Comparative analysis of pain-related medications used by patients with and without painful neuropathic disorders (PNDs)

\begin{tabular}{lccc}
\hline & $\begin{array}{c}\text { Patients with } \\
\text { PNDs, n (\%) }\end{array}$ & $\begin{array}{c}\text { Patients without } \\
\text { PNDs, n (\%) }\end{array}$ & $\chi^{2}$ \\
\hline Anticonvulsants & $679(13.8)$ & $136(2.8)$ & $\mathrm{P}<0.001$ \\
Antidepressants & $1230(25.0)$ & $533(10.9)$ & $\mathrm{P}<0.001$ \\
NSAIDs & $2611(53.2)$ & $1411(28.7)$ & $\mathrm{P}<0.001$ \\
Opioids & $951(19.4)$ & $198(4.0)$ & $\mathrm{P}<0.001$ \\
Benzodiazepines & $1547(31.5)$ & $1043(21.2)$ & $\mathrm{P}<0.001$ \\
Corticosteroids & $1032(21.0)$ & $518(10.5)$ & $\mathrm{P}<0.001$ \\
Muscle relaxants & $477(9.7)$ & $108(2.2)$ & $\mathrm{P}<0.001$ \\
Sedatives and hypnotics & $205(4.2)$ & $136(2.8)$ & $\mathrm{P}<0.001$ \\
\hline
\end{tabular}

NSAIDs Nonsteroidal anti-inflammatory drugs

present study represents a large number of subjects and a significant proportion of the covered population and did not limit the power of the study.

Another important limitation of this study is related to the use of ICD-9 codes to identify patients with PND. In Quebec, physicians are not required to record an ICD-9 code during an encounter with a patient. In addition, for each claim submitted to the RAMQ for reimbursement of a medical service, only one diagnosis can be written on the form. For patients with PND and other diseases, the diagnosis of PND can never be indicated if the diagnosis of such other disease is written instead. This may actually underestimate the real number of patients with PND. This limitation could be especially evident for patients with a DPN, for whom the diagnosis of diabetes may be reported but not the diagnosis of DPN. In fact, 27,854 patients with diabetes were identified in our database. Applying a prevalence of $10 \%$ to $15 \%(14,15)$ among diabetes would translate into 2785 to 4178 DPN patients. In contrast, only 100 patients with two diagnoses of PND were identified in the RAMQ database in 2002. This may also mean that patients with a diagnosis of DPN may represent more severe cases.

In addition, diagnostic information obtained from the claims can be subject to coding errors. To minimize this bias, at

\begin{tabular}{|c|c|}
\hline $\begin{array}{l}\text { Potentially inappropriate medication use in } \\
\text { older adults, independent of diagnosis or } \\
\text { conditions, according to Beers criteria }(11,12)\end{array}$ & n (\%) \\
\hline Indomethacine & $31(1.5)$ \\
\hline Pentazocine & $6(0.2)$ \\
\hline $\begin{array}{l}\text { Muscle relaxants and antispasmodics: methocarbamol, } \\
\text { carisoprodol, chlorzoxazone, cyclobenzaprine, oxybutynin }\end{array}$ & $138(6.8)$ \\
\hline Flurazepam & $59(2.9)$ \\
\hline Amitriptyline & $229(11.2)$ \\
\hline Doxepin & $17(0.8)$ \\
\hline Meprobamate & $0(0)$ \\
\hline $\begin{array}{l}\text { Short-acting benzodiazepines at doses greater than: } \\
\text { lorazepam } 3 \mathrm{mg} \text {, oxazepam } 60 \mathrm{mg} \text {, alprazolam } 2 \mathrm{mg} \text {, } \\
\text { temazepam } 15 \mathrm{mg} \text {, triazolam } 0.20 \mathrm{mg}\end{array}$ & $81(4.0)$ \\
\hline Long-acting benzodiazepines: chlordiazepoxide, diazepam & $54(2.6)$ \\
\hline Meperidine & $38(1.9)$ \\
\hline Ketorolac & $5(0.2)$ \\
\hline Long-term use of naproxen, oxaprozin or piroxicam & $144(7.1)$ \\
\hline Fluoxetine & $12(0.6)$ \\
\hline $\begin{array}{l}\text { Potentially inappropriate medication use in older } \\
\text { adults considering diagnoses or conditions }\end{array}$ & n (\%) \\
\hline Blood clotting disorders or anticoagulant therapy + NSAIDs & $74(3.6)$ \\
\hline Arrhythmias + tricyclic antidepressants & $15(0.7)$ \\
\hline COPD + long-acting benzodiazepines & $5(0.2)$ \\
\hline \multirow[t]{2}{*}{ Any of above } & n (\%) \\
\hline & $690(33.8)$ \\
\hline
\end{tabular}

COPD Chronic obstructive pulmonary disease; NSAIDs Nonsteroidal antiinflammatory drugs

least two similar diagnoses of a PND in 2002 were necessary to be included in the cohort. This approach yielded good specificity when claims data were compared with patient survey and medical record abstraction to assess the prevalence of hypertension (16). Unfortunately, it was not possible to conduct such validation, because the information in the RAMQ database was anonymous. Therefore, the magnitude of coding 


\section{TABLE 5}

Comparative analysis of health services resources used by patients with and without painful neuropathic disorders (PNDs)

\begin{tabular}{lccc}
\hline & $\begin{array}{c}\text { Patients } \\
\text { with PNDs } \\
\text { (mean } \pm \text { SD) }\end{array}$ & $\begin{array}{c}\text { Patients } \\
\text { without PNDs } \\
\text { (mean } \pm \text { SD) }\end{array}$ & ANOVA \\
\hline Visits to GPs & $6.7 \pm 13.5$ & $3.4 \pm 8.1$ & $\mathrm{P}<0.001$ \\
Visits to specialists & $8.0 \pm 14.0$ & $3.0 \pm 7.7$ & $\mathrm{P}<0.001$ \\
GP procedures & $5.4 \pm 8.0$ & $2.2 \pm 3.8$ & $\mathrm{P}<0.001$ \\
Specialist procedures & $10.3 \pm 14.8$ & $3.6 \pm 7.6$ & $\mathrm{P}<0.001$ \\
Days of hospitalization & $2.9 \pm 9.4$ & $1.1 \pm 5.1$ & $\mathrm{P}<0.001$ \\
\hline
\end{tabular}

GP General practitioner

errors in the present assessment remains unknown but was probably low given the applied inclusion criteria. On the other hand, because PND patients were identified by the proper ICD-9 code at least twice in their medical services information in 2002, this implies that they would have seen a physician on at least two occasions in 2002. Therefore, PND patients who would not have seen a physician during that year could not be included in the PND group. Consequently, results of the present study pertain to PND patients who were actively followed by a physician in 2002. A similar approach was taken by Berger et al (4) for selecting PND and non-PND patients.

Another limitation of the present study is that it is not possible to associate specific health resource consumption (medication or medical service) to a specific diagnosis based on the claims data. To overcome this issue, incremental comparisons with a non-PND, matched control group were made. The number of days of hospitalization was estimated using the location of the physicians' encounters reported in the RAMQ database. This probably underestimated the number of days in hospital, because days in-hospital during which a patient has not seen a physician were not taken into account. Finally, in accordance with the publicly funded health plan perspective adopted for the present study, cost estimates where limited to direct health care costs supported by the provincial health plan. From a societal perspective, if costs associated with productivity losses and patients' out of pocket expenses were taken into account, the economic impact of PND would be even higher.

Finally, there are some limitations associated with the analysis of potentially inappropriate medications using the Beers criteria. These criteria are based on specific medications and do not take into account other problems related to

\section{REFERENCES}

1. Merskey H, Bogduk N, eds. Classification of Chronic Pain: Descriptions of Chronic Pain Syndromes and Definitions of Pain Terms, 2nd edn. Seattle: 1ASP Press, 1994.

2. Dworkin RH. An overview of neuropathic pain: Syndromes, symptoms, signs, and several mechanisms. Clin J Pain 2002;18:343-9.

3. Haythornthwaite JA, Benrud-Larson LM. Psychological aspects of neuropathic pain. Clin J Pain 2000;16(Suppl 2):S101-5.

4. Berger A, Dukes EM, Oster G. Clinical characteristics and economic costs of patients with painful neuropathic disorders. J Pain 2004;5:143-9.

5. Huse DM, Oster G, Killen AR, Lacey MJ, Colditz GA. The economic costs of non-insulin-dependent diabetes mellitus. JAMA 1989;262:2708-13.

6. Rathmann W, Haastert B, Giani G. Drug prescriptions and costs in diabetic polyneuropathy. Dtsch Med Wochenschr 1999;124:681-6.
TABLE 6

Comparative analysis of annual costs of health services resources used by patients with and without painful neuropathic disorders (PNDs)

\begin{tabular}{lccc}
\hline & $\begin{array}{c}\text { Patients } \\
\text { with PNDs } \\
\text { (mean } \pm \text { SD) }\end{array}$ & $\begin{array}{c}\text { Patients } \\
\text { without PNDs } \\
\text { (mean } \pm \text { SD) }\end{array}$ & ANOVA \\
\hline Visits to GP & $\$ 164 \pm 285$ & $\$ 92 \pm 187$ & $\mathrm{P}<0.001$ \\
Visits to specialists & $\$ 292 \pm 462$ & $\$ 105 \pm 255$ & $\mathrm{P}<0.001$ \\
GP procedures & $\$ 137 \pm 223$ & $\$ 60 \pm 115$ & $\mathrm{P}<0.001$ \\
Specialist procedures & $\$ 416 \pm 625$ & $\$ 144 \pm 420$ & $\mathrm{P}<0.001$ \\
Days of hospitalization & $\$ 1,803 \pm 5,876$ & $\$ 662 \pm 3,212$ & $\mathrm{P}<0.001$ \\
Medication cost & $\$ 1350 \pm 1,939$ & $\$ 781 \pm 1,429$ & $\mathrm{P}<0.001$ \\
Total & $\$ 4,163 \pm 7,536$ & $\$ 1,846 \pm 4,418$ & $\mathrm{P}<0.001$
\end{tabular}

GP General practitioner

underuse or interactions of drugs among elderly patients. For example, while gabapentin is not in the list of Beers criteria, more than $50 \%$ of the PND patients receiving gabapentin had a daily dose of less than $900 \mathrm{mg}$, which appears to be a suboptimal dosage, knowing that at the end of randomized clinical trials of gabapentin in $\mathrm{NeP}$, patients received daily doses of $1800 \mathrm{mg}$ or more of gabapentin (17-20). The Beers list of medications may also be too rigid, because the use of a medication may be appropriate for a specific patient if other 'appropriate' medications were tried but were ineffective or caused side effects. For example, low doses of amitriptyline have been deemed appropriate for the treatment of $\mathrm{NeP}$ in adults (21). Finally, other tricyclic antidepressants, which may have fewer side effects than amitriptyline, were not included in the Beers list. Nonetheless, our results indicated that $36 \%$ of 559 amitriptyline users have a potential drug interaction, contraindication or warning as per the amitriptyline monograph, although this does not necessarily mean that amitriptyline was inappropriately used in these patients.

Despite these limitations, the results of the present analysis confirm that the economic burden of $\mathrm{NeP}$ is substantial. In addition, the analysis of the RAMQ database indicates that there is a high prevalence of comorbidities among patients with a diagnosis of a PND. Also of concern is that the analysis indicates that approximately one-third of these patients older than 65 years of age receive potentially inappropriate painrelated medications.

ACKNOWLEDGEMENT: The present study was supported by Pfizer Canada Inc, Kirkland, Quebec.

7. Davies L, Cossins L, Bowsher D, Drummond M. The cost of treatment for post-herpetic neuralgia in the UK. Pharmacoeconomics 1994;6:142-8.

8. Meyer-Rosberg K, Kvanstrom A, Kinnman E, Gordh T, Norfors LO, Kristofferson A. Peripheral neuropathic pain a multidimentionnal burden for patients. Eur J Pain 2001;5:379-89.

9. Oster G, Berger A, Dukes E, Edelsberg J, McCarberg B. Use of potentially inappropriate pain-related medications in older adults with painful neuropathic disorders. Am J Geriatr Pharmacother 2004;2:163-70.

10. Von Korff M, Wagner EH, Saunders K. A chronic disease score from automated pharmacy data. J Clin Epidemiol 1992;45:197-203.

11. Beers MH. Explicit criteria for determining potentially inappropriate medication use by the elderly. An update. Arch Intern Med 1997;157:1531-6. 
12. Fick DM, Cooper JW, Wade WE, Waller JL, Maclean JR, Beers MH. Updating the Beers criteria for potentially inappropriate medication use in older adults: Results of a US consensus panel of experts. Arch Intern Med 2003;163:2716-24. (Erratum in 2004;164:298.)

13. Eisenberg MJ, Filion KB, Azoulay A, Brox AC, Haider S, Pilote L. Outcomes and cost of coronary artery bypass graft surgery in United States and Canada. Arch Intern Med 2005;165:1506-13.

14. Backonja MM. Pathogenesis and treatment of neuropathic pain in older adults. Am J Pain Manag 2004;14(Suppl 2):9S-13S

15. Daousi C, MacFarlane IA, Woodward A, Nurmikko TJ, Bundred PE, Benbow SJ. Chronic painful peripheral neuropathy in an urban community: A controlled comparison of people with and without diabetes. Diabet Med 2004;21:976-82.

16. Quam L, Ellis LB, Venus P, Clouse J, Taylor CG, Leatherman S. Using claims data for epidemiologic research. The concordance of claims-based criteria with the medical record and patient survey for identifying a hypertensive population. Med Care 1993;31:498-507.
17. Serpell MG; Neuropathic pain study group. Gabapentin in neuropathic pain syndromes: A randomised, double-blind, placebocontrolled trial. Pain 2002;99:557-66.

18. Rice AS, Maton S; Postherpetic Neuralgia Study Group. Gabapentin in postherpectic neuralgia: A randomised, double blind, placebo controlled study. Pain 2001;94:215-24.

19. Rowbotham M, Harden N, Stacey B, Bernstein P, Magnus-Miller L. Gabapentin for the treatment of postherpetic neuralgia: A randomized controlled trial. JAMA 1998;280:1837-42.

20. Backonja M, Beydoun A, Edwards KR, et al. Gabapentin for the symptomatic treatment of painful neuropathy in patients with diabetes mellitus: A randomized controlled trial. JAMA 1998;280:1831-6

21. Zhan C, Sangl J, Bierman AS, et al. Potentially inappropriate medication use in the community-dwelling elderly: Findings from the 1996 Medical Expenditure Panel Survey. JAMA 2001;286:2823-9. 


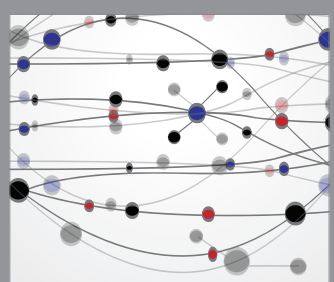

The Scientific World Journal
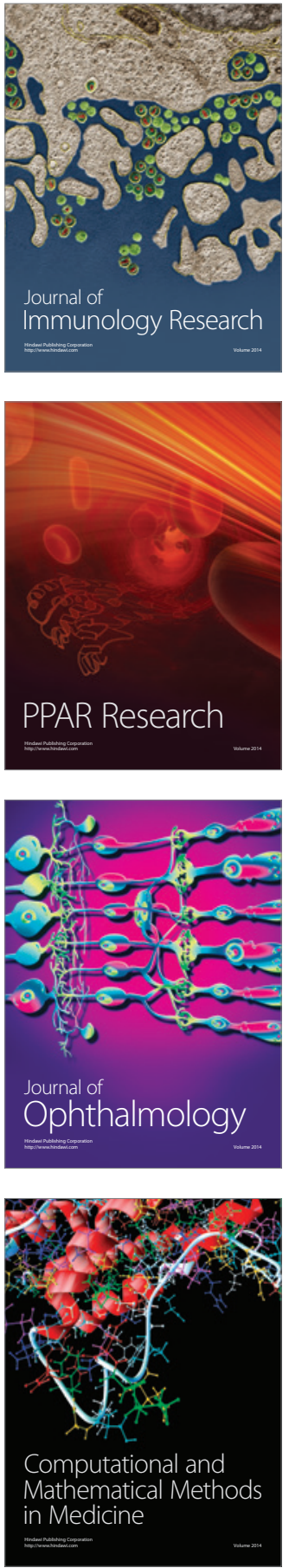

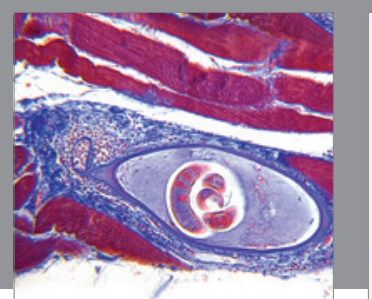

Gastroenterology Research and Practice

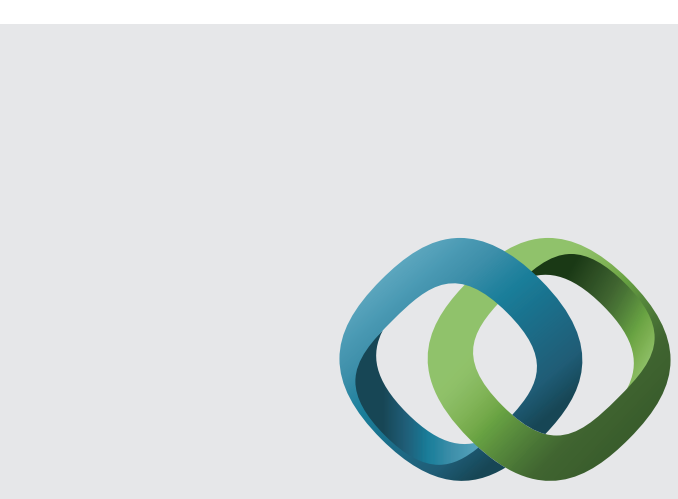

\section{Hindawi}

Submit your manuscripts at

http://www.hindawi.com
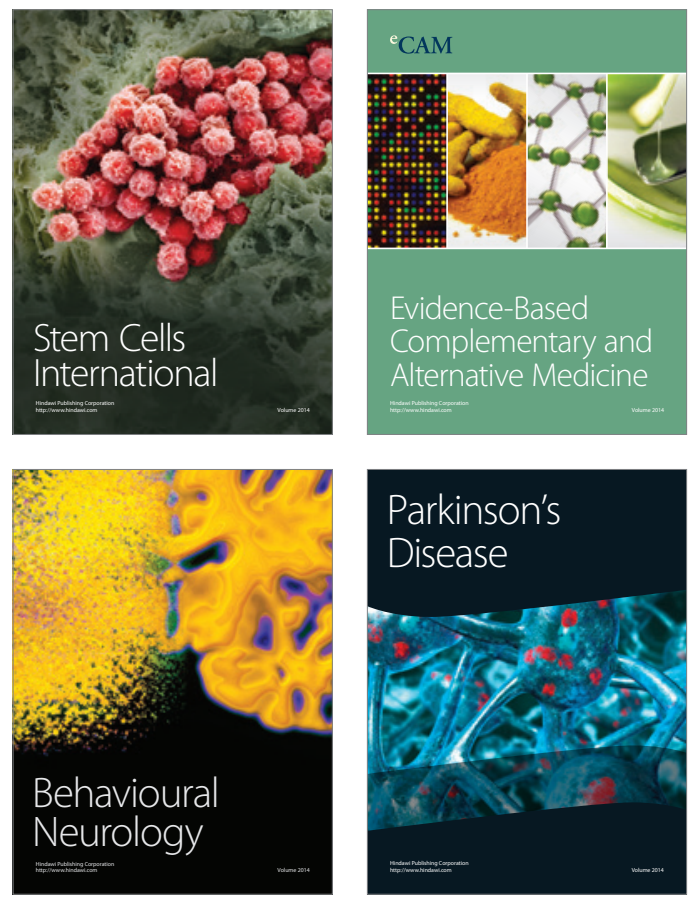
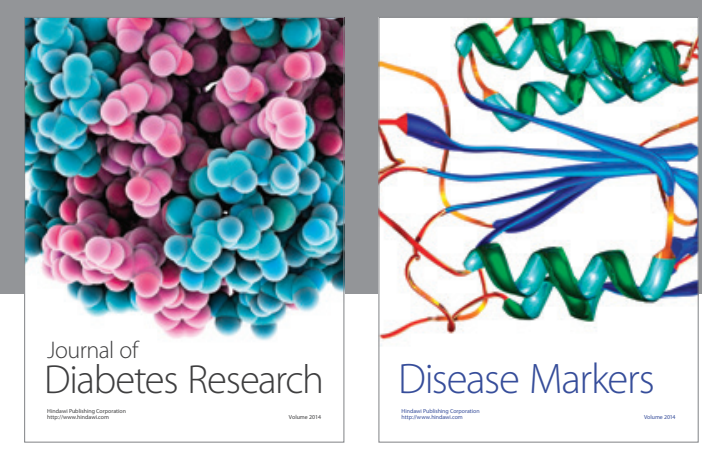

Disease Markers
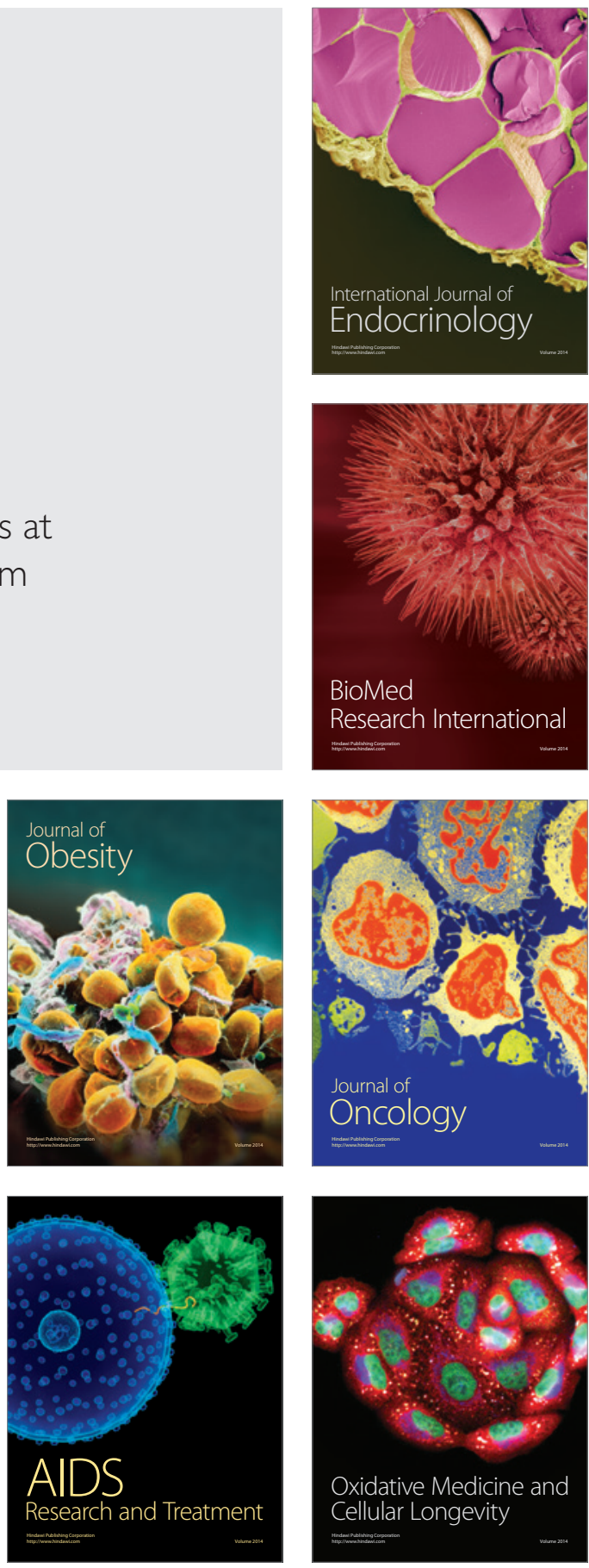